\title{
AN UNUSUAL FOREIGN BODY IN UPPER LIP: A CASE REPORT
}

Shankar Tati ${ }^{1}$, K. V. N. Durga Prasad ${ }^{2}$, P. Benjamin R. Kumar ${ }^{3}$, Juveria Majeed ${ }^{4}$, A. Surekha ${ }^{5}$

\section{HOW TO CITE THIS ARTICLE:}

Shankar Tati, K. V. N. Durga Prasad, P. Benjamin R. Kumar, Juveria Majeed, A. Surekha. "An Unusual Foreign Body in Upper Lip: A Case Report". Journal of Evolution of Medical and Dental Sciences 2015; Vol. 4, Issue 06, January 19; Page: 1072-1075, DOI: 10.14260/jemds/2015/151

ABSTRACT: Foreign body ingestion or insertion in oral cavity are uncommon, but can be deposited either by road traffic accident, injury or iatrogenic. Among the commonly encountered iatrogenic foreign bodies are broken instruments, needles, plastic and glass embedded pieces in soft tissues of oral cavity. In our case the foreign body is a metal piece being lodged in the upper labial mucosa accidentally, removed by sub labial approach.

KEYWORDS: Foreign body, Labial Vestibule, Metal Piece, Oral mucosa, Penetrating injury.

INTRODUCTION: The face and oral cavity is very sensitive parts and easily approachable for the accidental penetrating foreign body ingestion. (Fig No.1)

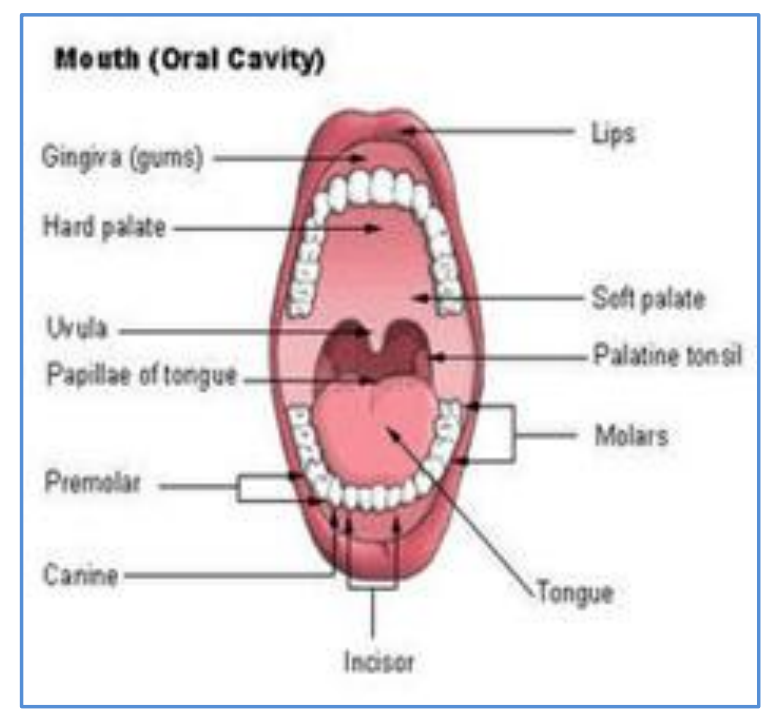

Fig. 1: Oral Cavity

Foreign body ingestion or insertion in to the oral cavity are rare and can occur due to trauma or can be iatrogenic. Foreign body can cause pain, swelling, abscess formation, septicemia, can also undergo distant embolization. Motor vehicle accidents, assault and bullet wounds are common cause for ingestion of foreign bodies, this foreign bodies can causes tissue reaction to foreign materials when embedded in the oral cavity can from a granuloma formation.

CASE REPORT: A 22 male patient reported to the emergency department of Govt. ENT Hospital, Koti, Hyderabad with complaint of penetrating foreign body in upper lip accidently 3 days back, there was no history of associated pain or swelling. Patient admitted and X-ray PNS was advised (Fig No.2) shown sharp radiopaque foreign body seen above the upper incisors. 


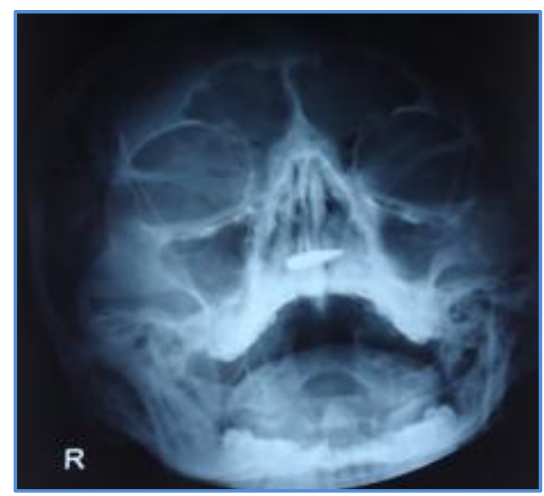

Fig. 2: X-Ray PNS

Subsequently patient was investigated to remove the foreign body under general anesthesia, all the investigations within normal limits, under endotracheal intubation, $2 \%$ xylocaine infiltration given in upper sub labial area, Horizontal incision is given on (R) side, foreign body (Hard metal piece) identified and removed, suturing done with $3^{0}$ catgut patient recovery was uneventful, discharged on $7^{\text {th }}$ day.

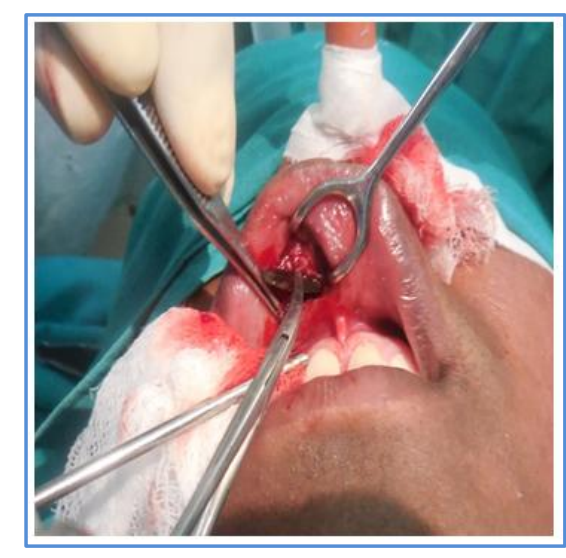

Fig. 3: Intra Operative Photo

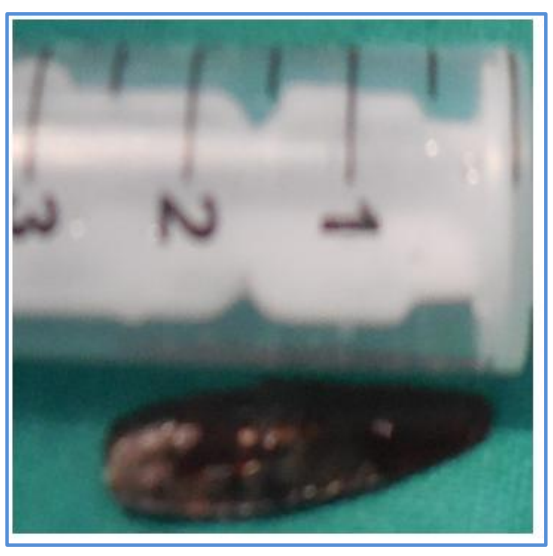

Fig. 4: Foreign body

DISCUSSION: Metal piece is always radiopaque, the visibility of different materials on plain radiographs depend on their ability to attenuate $\mathrm{x}$-rays, foreign body may be visualized, depending on their inherent radio density and proximity with the tissues in which they are embedded,(1) clinical evaluations and diagnosis of foreign body reactions pose a challenge as they depend on the type of foreign body involved, the duration of its presence, symptoms associated, motor vehicle and industrial accidents probable account for majority of cases,(2) a careful evaluation of the radiographs is essential as the foreign bodies have different radio densities, sizes and shapes. Their appearance is influenced by a number of factors which include its power to attenuate the x-ray beam which determine its radio density super imposition of these objects with the anatomic hard tissue structures and the exposure parameters. ${ }^{(3)}$ 
Any materialistic substance which is not native to the human body is a foreign object and will evoke an immune response as foreign body reaction resulting in a granuloma formation. There are circumstances in which the substances that provoke the acute inflammatory reaction are particulate and larger than the phagocytes and could not be digested by the reacting neutrophils causing a response namely granulomatous inflammation, the macrophages are the basic structural unit of chronic inflammation. After amassing substances that they cannot digest macrophages develop to epitheloid cells,(4) imaging the maxillofacial region with orthopantamograph was challenging as the metal piece appeared radiopaque and its position was in plane with the shadow of the hard palate. A careful evaluation of the radio density and the deviation of the normal anatomic structure of the hard palate on the right side were evaluated to locate the foreign body however an IOPA of the lip would have been more informative and evaluative, hannon et al reported a silica granuloma of the lip ${ }^{(5)}$ odell et al reported a foreign body giant cell reaction elicited by a haemostatic alginate,(6) owens et al published a study showing oral amalgam tattoos accounted for almost 1\% of approximately 19000 pathology reports on file,(7) Ding et al reported foreign body granuloma in the sub mental region due to fish bone. ${ }^{(8)}$ Although foreign body reactions are commonly associated with trauma related events, it is important to investigate and evaluate them with utmost care. A proper history, clinical evaluation and the appropriate investigation will help us in diagnosis and treatment of these conditions with accuracy.

In patients who have had penetrating injury the nature of foreign body determines the clinical behavior, inert objects such as steel and glass may not cause a significant inflammation to warrant their removal, ${ }^{(9)}$ removal of organic foreign body is sometimes mandatory as it may cause secondary infection, with abscess and fistula formation.(10)

CONCLUSION: Clinical evaluations and diagnosis of foreign body reactions pose a challenge as they depend on the type of foreign body involved, the duration of its presence, symptoms associated and the clinical picture, present case of foreign body was a metal piece, diagnosed by history and radiological evaluation, surgically removed by sub labial approach, uneventfully.

\section{REFERENCES:}

1. Mahale AR, Shetty R. Venugopal A, Kumar A, Radiological detection of unsuspected foreign bodies-letter to editor. Indian J. Radiol imaging 2002; 12: 134.

2. Hunter TB, Taljanovic MS. Foreign bodies. Radiographics 2003; 23: 731-51.

3. Anderson MA, Newmeyer WL, Kilgore Es. Diagnosis and treatment of retained foreign bodies in hand. Am J Surg 1982; 144: 63-67.

4. Sumanth KN, Boaz K, Shetty NY, Glass embedded in the labial mucosa for 20 years. Indian J Dent Res. 2008; 19 (2): 160-161.

5. Hannon SM, Pickett AB, Frost JM, foreign body (silica) granuloma of the lip. J Oral Maxillofac Surg. 1983; 41: 470-472.

6. Odell EW, Oades $\mathrm{P}$, Lombardi T. Symptomatic foreign body reaction to haemostatic alginate. $\mathrm{Br} \mathrm{J}$ Oral Maxillofac Surg. 1994; 32: 178-179.

7. Silveira VAS, Carmo EDD, Colombo CED, Cavalcante ASR, Carvalho YR. Intraosseous foreignbody granuloma in the mandible subsequent to a 20 year old work-related accident. Med Oral Patol Oral Cir Bucal 2008; 13 (10): 657-660. 


\section{CASE REPORT}

8. Ding X, Zhu XH, Fang YM, Zhang L. Foreign body granuloma in the submental region due to fish bone: a case report. Oral Surge3ry 2010: 3: 43-46.

9. RE. Experimental oral foreign body reactions: Commonly employed dental materials. Oral Surg Oral Med Oral Pathol 1990; 69: 713-9.

10. Sumanth KN, Boaz K. Shetty NY. Glass embedded in labial mucosa for 20 years Indian J Dent Res 2008; 19: 160-1.

\section{AUTHORS:}

1. Shankar Tati

2. K. V. N. Durga Prasad

3. P. Benjamin R. Kumar

4. Juveria Majeed

5. A. Surekha

\section{PARTICULARS OF CONTRIBUTORS:}

1. Professor, Department of ENT, Osmania Medical College, Hyderabad.

2. Assistant Professor, Department of ENT, Osmania Medical College, Hyderabad.

3. Assistant Professor, Department of ENT, Osmania Medical College, Hyderabad.
4. Resident, Department of ENT, Osmania Medical College, Hyderabad.

5. Resident, Department of ENT, Osmania Medical College, Hyderabad.

\section{NAME ADDRESS EMAIL ID OF THE} CORRESPONDING AUTHOR:

Dr. Shankar Tati, \# 12-5-149/6/A, Flat No. 201, Sajjas Ambiance, Vijaya Puri, Tarnaka, Secunderabad-17, Telangana. E-mail:drshankar_ms@yahoo.com

Date of Submission: 31/12/2014. Date of Peer Review: 01/01/2015. Date of Acceptance: 09/01/2015. Date of Publishing: 19/01/2015. 